\title{
Das amas de leite às mães órfãs: reflexões sobre o direito à maternidade no Brasil
}

\author{
From wet nurses to orphaned mothers: reflections on the right to \\ maternity in Brazil
}

Alzira de Oliveira Jorge (https://orcid.org/0000-0003-1366-1732) ${ }^{1}$
Monica Garcia Pontes (https://orcid.org/0000-0002-6425-7636) ${ }^{2}$
Adriana Fernandes Carajá (https://orcid.org/0000-0003-0824-925X) ${ }^{3}$
Gabriela Maciel dos Reis (https://orcid.org/0000-0002-4580-8228) ${ }^{4}$
Luciana de Souza Braga (https://orcid.org/0000-0003-4499-6316) ${ }^{1}$
Marcelo Grossi Araújo (https://orcid.org/0000-0002-1483-3818) ${ }^{4}$
Sonia Lansky (https://orcid.org/0000-0001-5533-4858)
Laura Camargo Macruz Feuerwerker (https://orcid.org/0000-0001-6237-6167) ${ }^{6}$

${ }^{1}$ Faculdade de Medicina, Universidade Federal de Minas Gerais. Av. Prof. Alfredo Balena 190, Santa Efigênia. 30130-100 Belo Horizonte MG Brasil. alziraojorge@gmail.com ${ }^{2}$ Hospital Risoleta Tolentino Neves, Universidade Federal de Minas Gerais. Belo Horizonte MG Brasil. ${ }^{3}$ Programa de PósGraduação em Antropologia, Faculdade de Filosofia e Ciências Humanas, Universidade Federal de Minas Gerais ${ }^{4}$ Programa de PósGraduação em Enfermagem, Escola de Enfermagem, Universidade Federal de Minas Gerais. Belo Horizonte MG Brasil. ${ }^{5}$ Secretaria Municipal de Saúde de Belo Horizonte. Belo Horizonte MG Brasil ${ }^{6}$ Faculdade de Saúde Pública, Universidade de São Paulo. São Paulo SP Brasil.

\begin{abstract}
This article addresses the compulsory seizing of children from vulnerable women in Brazil. Its objectives were: to discuss the violation of the right to maternity; to present the imposed restrictions especially on poor, black and indigenous women; the strategic control over their lives and children, and the resistance movements that oppose segregation. The sources of the research were: narratives of women in vulnerable situations, family members and health workers; interviews with strategic actors; document analysis; field journal. It became evident that vulnerabilities-linked to the criminalization of poverty and racial prejudice- have justified these separations. The lack of responsibility that State and society practice towards the support network for women, the devaluation of non-hegemonic productions of maternity, and the reinforcement of a 'reason of the world', that produces violence as a tool for exclusion establishing practical limits on the right to maternity. Women and children are disregarded in their singularities. Resistance movements have shown that intersectoral dialogues are an alternative to overcome discrimination and vulnerabilities.
\end{abstract}

Key words Ethnic violence, Gender based violence, Sexual and reproductive rights
Resumo $O$ artigo aborda a retirada compulsória de filhos de mulheres em situação de vulnerabilidade no Brasil. Objetivou-se refletir sobre a violação do direito à maternidade; apresentar os limites impostos, especialmente às mulheres pobres, negras e indígenas e as estratégias de controle sobre sua vida e de seus filhos; e os movimentos de resistência que se contrapõem às segregações. Foram fontes da pesquisa: narrativas de mulheres em situação de vulnerabilidade, de familiarese trabalhadores da saúde; entrevistas com atores estratégicos; análise documental; diários de campo. Evidenciou-se que vulnerabilidades atreladas à criminalização da pobreza e ao preconceito racial têm justificado as separações. A desresponsabilização do Estado e da sociedade quanto à formação de uma rede de apoio às mulheres, a desvalorização de produçães não hegemônicas de maternidades e o reforço de uma razão de mundo que produz a violência como ferramenta para exclusão vão conformando limites práticos quanto ao direito à maternidade. Mulheres e seus filhos são desconsiderados em suas singularidades. Os movimentos de resistência mostraram que diálogos intersetoriais são uma alternativa para superar discriminações e vulnerabilidades.

Palavras-chave Violência étnica, Violência de gềnero, Direitos sexuais e reprodutivos 


\section{Introdução}

A Constituição Federal da República Federativa do Brasil de 1988 incluiu a proteção à maternidade como direito social. Porém, muitas mulheres ainda enfrentam barreiras para exercer o direito à maternidade, sofrendo a retirada de seus filhos por imposição do Estado. As bases desse tipo de violência foram estabelecidas no Brasil Colônia. Há informações do século XVI sobre a separação compulsória de mães indígenas de seus filhos: mulheres que foram abusadas e escravizadas pelos colonizadores e ainda tiveram seus filhos sequestrados. As crianças eram apartadas de suas culturas e perdiam seus nomes, vínculos familiares e étnicos. A catequização das crianças indígenas por padres e missionários corroborava a aculturação a serviço dos valores do colonizador ${ }^{1}$.

Apesar de existirem indícios da retirada dessas crianças de suas famílias no Brasil colonial, há carência de pesquisas e comprovação documen$\mathrm{tal}^{2}$. As restrições impostas às mães incluíam o ato de amamentar, situação revertida posteriormente para que as indígenas pudessem aleitar os filhos dos colonizadores. Assim, foram instituídas as amas de leite no Brasil ${ }^{3}$.

Com o tráfico de escravos negros, a partir do século XVII, mulheres negras e suas crianças também passaram a ser alvo dessas violências. As amas de leite passaram a ser as negras e seus filhos eram entregues para a escravidão ou para abrigos. Com a Lei do Ventre Livre, muitos filhos de escravas foram impedidos de viver com suas genitoras, apesar de trabalharem para o seu senhor até completarem 21 anos $^{2}$.

Durante a ditadura militar, a separação compulsória de mães e filhos envolveu tortura e assassinatos praticados pelos Centros de Informações da Marinha e de Operações de Defesa Interna ${ }^{4}$. No mesmo período, também há registro de violações cometidas pelo Serviço de Proteção ao Índio contra mulheres e crianças indígenas, com participação de militares, latifundiários e funcionários públicos ${ }^{5}$.

Além disso, a historiografia da separação compulsória de mães e filhos também inclui regimes de isolamento. Mulheres em hospitais psiquiátricos, com ou sem sofrimento mental, foram obrigadas a abdicar do convívio com seus filhos ${ }^{6}$. As práticas de isolamento e internação compulsórios também foram marcas da política de controle da hanseníase no Brasil: pessoas com a doença recolhidas em hospitais colônias e muitas crianças, separadas dos pais, segregadas em instituições totais ${ }^{7}$.
A luta pela redemocratização e pelos direitos humanos arrefeceu a prática dessas violências. Todavia, nos anos 2000, o poder público - por meio de decisões do Ministério Público e do Poder Judiciário - voltou a determinar a retirada de filhos de mães em situação de vulnerabilidade, alegando riscos para as crianças. Muitos bebês têm sido retirados de mães em uso de drogas e/ ou trajetória de rua ${ }^{8}$. Existem também relatos de sequestros de bebês de mães com deficiência visual, sofrimento mental, situação de privação de liberdade ou pertencimento a determinadas etnias, como as indígenas Guarani e Kaiowá que vivem no Mato Grosso do Sul (MS) ${ }^{2}$.

Em Belo Horizonte (BH), a prática institucional de abrigamento compulsório de filhos de mulheres empobrecidas ou em situação de vulnerabilidade, as mães órfã s, ganhou visibilidade a partir de 2014, quando foi oficializada por meio de instrumentos legais e provocou movimentos de resistência. Nas mesmas circuntâncias são relatadas separações compulsórias em Porto Alegre $^{9}$, São Paulo ${ }^{10}$ e Rio de Janeiro ${ }^{11}$.

A dor vivenciada por mães e filhos separados percorre gerações e compõe muitas histórias nem sempre relatadas em fontes oficiais. Este artigo busca refletir a respeito dessa violência provocada pelo cerceamento do direito de ser mãe no Brasil, apresentando as estratégias de controle e os limites impostos sobre as vidas de mulheres, especialmente pobres, negras e indígenas, e seus filhos, bem como os movimentos de luta que se contrapõem a essas segregações.

\section{Métodos}

O Observatório de Políticas e Cuidado em Saúde da Universidade Federal de Minas Gerais (UFMG), vinculado à Rede Nacional de Observatórios de Políticas Públicas em Saúde e Educação em Saúde, desde 2015 se dedica a compreender os sentidos dessa prática que separa compulsoriamente mães e filhos. Entre os produtos dessa frente de pesquisa estão três dissertações construídas a partir de abordagens qualitativas do tipo interferência, por meio de exercícios cartográficos.

A pesquisa interferência é um modo de investigação que não pressupõe intervenção sobre o outro, mas admite, a partir da interação, a presença de ruídos e incômodos que provocam deslocamentos institucionais e pessoais. Trata-se de um modo exigente de pesquisar, que requer uma escuta minuciosa do outro e uma harmonia 
criativa para tornar possível uma interação emaranhada à produção da vida ${ }^{12}$.

Por sua vez, a cartografia propõe dar visibilidade a enunciados sociais acompanhando processos complexos, rompendo com olhares superficiais acerca das situações e mergulhando nas intensidades que a heterogeneidade dos encontros humanos é capaz de produzir ${ }^{13}$. A produção de cartografias intrincadas aos tensionamentos que têm provocado a judicialização de vidas de pessoas vulnerabilizadas representou uma alternativa potente para "instaurar um outro combate" 14 , solidário e digno, para mães e filhos separados compulsoriamente. Nesse cenário, pesquisadores in mundo, atravessados pelos encontros produzidos ao longo das investigações, experimentam um "exercício de desaprendizagem do já sabido"15 e a produção de novas visibilidades.

Este artigo apresenta uma seleção dos principais achados das três dissertações produzidas no âmbito do Departamento de Medicina Preventiva e Social da Faculdade de Medicina da UFMG. Foram fontes primárias: a) dez narrativas de mulheres em situação de vulnerabilidade (uso de álcool e outras drogas, situação de rua, pobreza e negritudes, internações compulsórias devido à hanseníase), uma narrativa com familiar e duas com trabalhadores da saúde que acompanharam as separações; b) vinte entrevistas com atores estratégicos, sendo três gestores de maternidades e dez trabalhadores do Sistema Único de Saúde (SUS) em BH (nível central, maternidades, unidades básicas de saúde/UBS e consultórios de rua), um representante da Defensoria Pública, um do Conselho Municipal de Saúde, um do Conselho dos Direitos da Criança e do Adolescente, dois conselheiros tutelares, uma professora universitária do movimento feminista e uma advogada da Clínica de Direitos Humanos da UFMG.

A análise documental incluiu: atas de reuniões cedidas pela Secretaria de Segurança de $\mathrm{BH}$; relatórios técnicos e transcrições de audiências públicas; análises das normativas do MP e do Judiciário; relatórios disponibilizados por FUNAI, Conselho Indigenista Missionário, Núcleo de Promoção e Defesa dos Povos Indígenas da Defensoria Pública do MS; e o documento final da 6a Kunãgue Aty Guasu Kaiowá Guarani. Outras fontes utilizadas foram os diários de campo das pesquisadoras.

As narrativas foram relatos de experiência produzidos a partir de falas livres dos atores, que discorreram sobre suas experiências de vida rela- tivas à separação de mãe e filho, sem grandes interferências do pesquisador. As entrevistas foram conduzidas a partir de um roteiro previamente elaborado, sem a mesma liberdade.

Narrativas e entrevistas foram audiogravadas e transcritas. Todos esses contatos foram precedidos de explicação acerca da pesquisa e de assinatura do Termo de Consentimento Livre e Esclarecido, com garantia de sigilo e confidencialidade. A pesquisa foi aprovada pelos COEP da UFRJ, Secretaria Municipal de Saúde/BH e UFMG.

Do conjunto desse material foram selecionados extratos que contribuíram para dar visibilidade aos jogos de força e saberes que marcam a situação vivenciada por mães e filhos separados, num esforço analítico a respeito da garantia do direito de se tornar mãe no Brasil.

\section{Resultados e discussão}

Tentativas repetidamente atualizadas de domínio sobre as vidas de mulheres demarcam o fio condutor das investigações que sustentam este artigo. Ao expor a produção de maternidades que não se enquadram nos critérios de uma leitura hegemônica de mundo, foram deflagrados mecanismos de controle de imagens, discursos e percepções que fragilizam a mulher e distorcem os sentidos de suas vidas, bem como suas formas de resistência e oposição ao modelo colonialista contemporâneo $^{16}$. Nesse cenário, que desvaloriza e desconsidera a heterogeneidade das opções femininas ${ }^{17}$, os resultados deste trabalho evidenciam que os afetos são reduzidos a um sistema de normas que constrange possibilidades de criar novos e singulares modos de viver. Essas estratégias biopolíticas de controle sobre a vida ${ }^{18}$ acabam por aprisionar subjetivações e relações humanas úteis a determinado modo de organizar o mundo.

Fiquei 12 dias com ele na maternidade, mesmo tendo condições de amamentar, fui impedida, me deram remédio para meu leite secar, junto com o meu peito, meu coração chorava de dor. [...] nossos direitos fundamentais foram violentamente atropelados (narrativa de uma mãe).

Em diversos encontros, mulheres e trabalhadores também se interrogam sobre a idealização da figura materna.

Assim, quais são os requisitos pra ser uma boa mãe? [...] quais são os atributos que te dão o direito de criar seu filho ou não? Eu acho que isso é um assunto complexo que não cabe a um poder só definir isso (trabalhadora 1 da UBS). 
O modelo da mãe disponível, que organiza a vida em função dos filhos, é o parâmetro socialmente aceito para o exercício da maternidade ${ }^{19}$. Corresponde a um discurso que desconsidera as construções identitárias, a classe social, a espacialização e territorialidade e expõe mulheres a um tribunal coletivo, regulado por valores capitalistas e do colonialismo presente e forjado no racismo, na misoginia e no machismo ${ }^{16,20}$.

Nessa perspectiva, há uma avaliação disseminada de que mulheres em situação de vulnerabilidade são incapazes de gerir a própria vida. Perderam ou nunca tiveram protagonismo e legitimidade. Perdura o julgamento moral, a culpabilização da mulher e a recusa à possibilidade de superação de limites. Contudo, nos territórios estão explícitos os limites dessa compreensão:

Um pouquinho antes de 2014, fiquei impactada com uma gestante que vira e fala: "Não, eu quero ficar". Porque até então não tinha aparecido nenhuma gestante que falasse assim ou nenhuma mulher que dissesse, "Eu quero ficar com meu bebê". E ali a gente seguia um certo desejo que era o desejo da mãe, mas ao mesmo tempo, o que eu fui percebendo ao longo dos anos, é que essa mãe, na realidade, ela não pode nem ter o desejo a querer, né? Minha ficha depois caiu um pouquinho... Porque assim, mesmo se ela quiser, ela não vai ficar. Ela prefere dizer que não, porque senão ela vai alimentando o desejo... (narrativa de uma trabalhadora da saúde mental)

O desejo pela gravidez, a experiência da gestação e o exercício da maternidade são concebidos, aprioristicamente, como inapropriados para essas mulheres, ainda que as práticas de cuidado estejam inscritas na relação entre mãe e filho:

E aí, gente, eu lembro dos cabelinhos da menininha, essa cena não me esquece, nunca ia imaginar que isso ia acontecer. Um dia na unidade, eu lembro que eu brinco com ela, porque cheia de trancinha, aquelas trancinhas afro [...] Essa mãe perdeu o direito de ser mãe daquela que gestou porque disse que bebia (trabalhadora 2 da UBS).

É esse modo de perceber o mundo que opera em favor da retirada de filhos de mulheres em situação de vulnerabilidade ${ }^{21}$. Além da idealização da maternidade e das tentativas de eliminação de determinadas condições de existência femininas, a criminalização da pobreza também aparece como razão para justificar as separações.

Teve uma mãe, eu tenho que lembrar quem foi essa mãe porque me marcou demais, que falou pra mim sentada aqui: "Doutora, não consigo entender por que tiraram meu neto, só por que sou pobre? Se Jesus Cristo nasceu no meio da sujeira, dos bichos, aquilo não era família? Por que eu não posso ter minha família? Por que eu sou pobre? Por que eu moro do lado do esgoto?" (representante da Defensoria Pública).

As vulnerabilidades sociais emergem como os principais elementos nas disputas de narrativas que envolvem a situação das mães órfãs.

Não há uma mulher, nesses anos todos, do setor privado, denunciada. Nenhuma. Então, há uma discriminação explícita e forte nessa história e muito desconhecimento, muita expectativa que atende a interesses... (trabalhadora 1 do nível central).

Um movimento na perspectiva da criminalização da pobreza, como se essas mulheres que já estão tão vulneráveis e já estão em situação de rua, ou muitas vezes nem em situação de rua, mas fazendo uso ou que já fizeram uso de alguma substância psicoativa, como se elas não tivessem condição de cuidar dos seus próprios filhos. Então a gente vê um movimento forte do Judiciário mesmo, que é um Judiciário com seus alicerces branco, burguês, machista e na lógica patriarcal (trabalhadora do Consultório de Rua).

Eu fico pensando, qual mãe de classe média, tem várias alcoólatras, usuárias de substâncias ilícitas, será que essas mães tiveram seus filhos retirados? Então, será que é a droga, acho que tem... ou é também a pobreza, é o fato de ser negro? (trabalhadora 1 da UBS).

Praticamente em todas as narrativas e entrevistas a pobreza não constitui fator isolado de marginalização. Discriminações raciais e de gênero se misturam a essa condição, potencializando o abismo entre a idealização do feminino e da maternidade e a realidade vivenciada por mulheres brasileiras. Há quem escancare esse distanciamento:

E além de ser cena muito marcada por mulheres, percebi que era uma violência muito grande sobre essas mulheres também. Eram mulheres que trabalhavam pro tráfico, mas também que se prostituiam, que por exemplo faziam faxina, sobreviviam ali naquela cena. E me marcava também que elas ganhavam menos que os homens todas as vezes que elas ficavam, por exemplo, ou como olheira ou na boca ali como mula. Então até no tráfico de drogas a gente vê essa questão do gênero, do preconceito, do machismo. Como é que é também marcado, né? Até o tráfico marca isso muito. Outra coisa que me chamava a atenção: a maioria negra. Dessas oito que acompanhei em 2012, uma era branca (narrativa de trabalhadora da saúde mental).

Situações de vulnerabilidade também envolvem questões relativas à forte orientação patriar- 
cal, por sua vez relacionada à organização global da sociedade ${ }^{22}$. A formação social de dominação masculina produz ações de opressão sobre as mulheres, reforçando o estereótipo feminino domesticado e maternal. Além dessa situação, cabe destacar a produção da imagem da mulher negra sempre a serviço dos dominantes. Das amas de leite às mães órfãs, há grandes similaridades: mulheres permanecem expostas à violência e à desumanização do racismo resultantes da escravidão ${ }^{17,23,24}$. Facetas dessa insensibilidade persistem e gritam nas narrativas que envolvem as mães órfãs.

A minha avó, ela é filha de uma ex-escrava [...] o meu bisavô tirou ela com cinco anos de idade da mãe porque a mãe vivia numa extrema pobreza. [...] Minha vó chegou a fugir algumas vezes tentando voltar para mãe, né? Uma vez, meu bisavô chegou a bater nela, para que não tentasse voltar mais (narrativa de familiar).

Nesse contexto, faz-se necessário um olhar singular para a maternidade da mulher negra ao longo da história. Quantas vezes o exercício do direito à maternidade da mulher negra foi subtraído para servir ao desejo do branco? Ora produzindo leite para o filho da mulher branca, ora deixando de cuidar dos seus filhos para cuidar dos filhos da mulher branca, ora gerando filhos do seu dono. O que essa assimetria nos diz? ${ }^{17}$

Quem sabe se for tirando, né, essas crianças da pobreza, tirando da mãe, a gente vai se tornar um país mais puro, mais hitleriano né. Sei lá, mas acho que é isso, será que eles pensam que vão conseguir purificar essa raça brasileira através de proporcionar alguma coisa diferente do que é a criação por um negro? Por um pobre? Sei lá, eles devem pensar alguma coisa assim (trabalhadora 2 da UBS).

$E$, do meu ponto de vista, eles estão usando esse saber médico, esse poder médico, a ciência travestida de poder médico, e também o poder travestido de ciência, pra dizer que a hora certa de pegar essas crianças, de limpar a área, limpar a raça e melhorá -la, porque é higienista. Seria isso, pegar esses bebês e dar a eles uma formação diferente da que eles têm hoje enquanto uma sub-raça humana, zumbis, imprestáveis (trabalhadora 1 do nível central).

Davis $^{25}$ relata que, com o fim do tráfico de pessoas, a reprodução das mulheres negras era a única maneira de aumentar o número de escravos, especialmente por meio de estupros. Elas eram avaliadas em função de sua fertilidade, como instrumento para garantir a força de trabalho escravo. Essa figura da mulher negra como útero gerador de crianças úteis ao modo de vida dominante persiste. Elas são as principais prota- gonistas das narrativas de separação forçada entre mães e filhos.

$\mathrm{Na}$ atualidade, a precariedade de políticas de proteção social fabrica a vulnerabilização dessas mulheres, que junto à não efetivação de uma rede de cuidado, justificam a produção de medidas cautelares, que pressupõem que essas condições tornariam essas mulheres propensas a efetuar maus tratos ou mesmo serem negligentes com suas crianças.

Garantir aí, conforme tá na Portaria descrito, evitar que crianças fiquem na questão do risco direto, né. Os valores da questão de manter aí a integridade física da criança (representante Conselho Tutelar).

Eles falam isso muito: "Já que o SUS não funciona e que não existe o serviço de saúde tal para dar conta da epidemia do crack, nós precisamos proteger esta criança" trabalhadora 1 do nível central.O argumento que... de natureza, supostamente ética, é de proteção da criança, ou seja, né. Pais que são usuários não teriam condição de cuidar da criança. E um pouco de uma concepção de um Estado que interfere, que tem poderes para interferir na unidade familiar, supostamente em nome da segurança da criança (gestor da maternidade 1).

Predomina um discurso produtor de seres esquecidos pelo Estado, mulheres ignoradas enquantos sujeitos e singularidades, mães em situação de vulnerabilidade consideradas descartáveis, quase lixos, ou como diria Butler ${ }^{26}$ "vidas não passíveis de luto".

É a mãe que presta ou é a mãe que não presta. E se ela não prestar, joga essa mãe no lixo, como se ela não tivesse direito ao cuidado. Acho que eles realmente enxergam a vida assim: essas pessoas não têm direitos, porque elas não têm jeito. E se não têm jeito é melhor descartar, aí descarta a mãe, a família, pega o bebê e vai cuidar (trabalhadora 1 do nível central).

Há muitas conexões entre os modos de segregação em diferentes realidades e momentos da história do Brasil. O discurso discriminatório, que julga determinados povos e condições sociais como impróprios para o exercício da maternidade, baseado na herança escravagista, ainda corresponde àquele que instrumentaliza ações ou políticas de saúde prescritivas e higienistas ${ }^{17}$. Não é uma coincidência. Essas práticas estão inseridas em um contexto de disputa que envolve tentativas de subjugar e até mesmo eliminar pessoas em determinadas situações de existência. É nesse contexto que são empreendidas ações como o isolamento compulsório e a retirada de filhos, a imposição dos preventórios e as adoções ilegais, com todas as suas consequências. 
Uma política que fracassa porque ela não tem os pressupostos éticos na sua atenção, porque ela não escuta o sujeito, né, ela prescreve pra mulher enquanto um objeto, que tem que ser obediente àquela prescrição (trabalhadora 1 do nível central).

Considerando o conjunto de fontes analisadas, foi possível identificar agentes do Estado como principais efetuadores das segregações. Essas atuações são evidentes na produção de normativas direcionadas às mães com hanseníase, em situação de rua, lar precário e/ou histórico de uso de drogas ou, ainda, nas intervenções sobre as vidas das indígenas.

Nesse sentido, o aparelho burocrático do Estado tem servido à organização e implantação de técnicas de controle sobre a sociedade e os corpos, cumprindo seu papel no que concerne às táticas de governamentalidade ${ }^{18}$. A utilização de instituições como maternidades públicas, Ministério Público e Vara da Infância e Juventude para separar mães e filhos sob pretextos de drogadição, pobreza extrema ou incapacidade de criar foi fornecendo pistas de que as separações compulsórias correspondem a uma estratégia de governo das vidas, que, ao penetrar nas mais intensas relações humanas, constitui uma prática violenta contra aqueles que se apresentam menos afinados com a razão hegemônica ${ }^{27}$.

Cabe destacar que a interferência do Estado, ora exercendo seu biopoder sobre corpos femininos e crianças, ora sem disposição política para a organização de uma rede de apoio, retira possibilidades de produção do cuidado e de vínculo de usuárias de quem, em princípio, deveria cuidar.

Elas colocam o tempo todo que o que falta épolítica pública para garantir uma condição de moradia para que ela sozinha com os filhos ou com seus companheiros e os filhos tenham condição de exercer a maternidade (trabalhadora do Consultório de Rua).

Então, a princípio, eu penso que a gente teria de dar uma chance pra essas mães, com apoio dessa sociedade porque isso não é responsabilidade só da mãe, é responsabilidade da sociedade... serviços de saúde, da justiça, dos movimentos, inclusive apoio com questões sociais... financeiras, não só em termos de atendimento, de acompanhamento, mas de manutenção de vida também (trabalhadora $1 \mathrm{da}$ UBS).

Tensões dentro da própria estrutura do Estado reforçam disputas de projetos de sociedade, de vida, de saúde, entre modelos de atenção para favorecer ou não um cuidado que considere as singularidades dos usuários. Há quem sustente a importância de mães e filhos crescerem juntos, mas há aqueles que argumentam que situações de vulnerabilidade justificam a separação, absolutizando limites e negando possibilidades, sem medir os efeitos devastadores sobre tantas existências. Contudo, a escuta atenta e a sensibilidade de profissionais que percebem as sutilezas que envolvem as vidas dessas mulheres vem contribuindo para a produção de novos caminhos.

Contrapondo-se à crueldade, há também a busca realizada por mulheres e por diferentes agentes do Estado (trabalhadores da saúde, da justiça, da assistência social) para produzir novos sentidos para a vida. Nesse contexto, a implementação de políticas de cuidado relacionadas ao uso de álcool e outras drogas, à saúde sexual e reprodutiva e à saúde mental ganham destaque nas discussões que envolvem a segregação de mães e filhos na atualidade ${ }^{17,23}$.

Em relação ao modelo de atenção preconizado para abordar o uso de drogas, por exemplo, ainda é comum priorizar estratégias pouco eficazes baseadas na tríade abstinência, recaída e punição ${ }^{28}$.

Os indivíduos são singulares e estão habitando o mundo cada um de um modo, não há como normatizar e a gente padronizar como deve ser uma ação para um fenômeno tão complexo que é do uso de drogas na contemporaneidade, que vem inclusive para tamponar sintomas do sistema capitalista: desemprego, opressão de gênero, falta de moradia, de como toda a pirâmide organizacional na sociedade, que é de poucos violando muitos (trabalhadora do Consultório de Rua).

Estamos sendo instruídos a, quando formos ao juiz ou juíza, não falar que ela usa droga, porque eles não toleram, não entendem. Usou droga acabou. Droga ilícita, agora falar que está usando a clorpromazina, o Diazepam, o que for prescrito pelo psiquiatra pode. Eles não sabem o que é redução de danos, que eles não vão parar de usar drogas de uma hora para outra, que levam tempo [...] Acho que a sociedade inteira é preconceituosa, não reconhece o interesse da indústria de bebidas ou do tabaco que causa tanto mal comprovadamente e aí vão repercutindo esse preconceito com o usuário de crack, que é um preconceito social na verdade (trabalhadora 1 do nível central).

Apesar da alegada impossibilidade de uma mulher pobre usar drogas e conseguir criar filhos, mães relatam encontrar na maternidade um novo sentido para a vida e uma saída para diminuir o uso prejudicial de substâncias. Uso que é fruto dos modos de subjetivação contemporâneos, que impõem individualização, solidão 
e patologização dos sofrimentos, que afetam intensamente as mulheres.

Comecei a fazer uso de droga com cliente. [...] Eu disse à assistente social que queria uma casa para ter meu filho: "De perto do meu filho eu não saio". Ela me acolheu. [...] Deu certo. E o que eu mais quero agora é poder ver minha família, todos eles (narrativa de Maria M.).

Então, a mãe, ela se vê em uma oportunidade de rever um vínculo com a própria vida e isso é uma coisa que a gente deveria buscar ofertar e garantir (gestor da maternidade 2).

Recolhemos no campo muitas experiências em que a maternidade se tornou fonte potencial de cuidado de si, abrindo possibilidade de pactuação com a vida e se configurando como dispositivo socioafetivo para superação de uso prejudicial de álcool e outras drogas ${ }^{29}$. Reis et al ${ }^{30}$ pontuam que a vivência do processo gravídico pode ser repleta de significados, estimulando as mulheres a projetarem atos futuros, como a seguir:

[...] a maternidade pode ser um momento de ressignificação da condição enquanto mulher na sociedade. Então não tem nada que embase que uma mulher que faz uso de alguma substância psicoativa não possa ficar com a guarda do seu filho (trabalhadora do Consultório de Rua).

Então, eu fico pensando... será que a justiça, isoladamente, sem ouvir essas mães, será que tem condição de simplesmente porque é uma pessoa que vai ter mais dificuldade de criar esse filho, mas será que com o suporte da sociedade, será que com o suporte do serviço de saúde, dos movimentos sociais, da própria justiça, né? Se o desejo dela é de criar e de manter esse filho, essa maternidade... Será que não seria até uma possibilidade de ressurgimento, de cura? Ou mesmo que não de cura, de redução de dano, de uma vida mais funcional pra essa mulher? (trabalhadora 1 da UBS).

Isso reforça a premência de se dar visibilidade à interdependência entre as relações que envolvem raça, gênero, classe e cultura. Remete à necessidade de se considerar diversos fatores de discriminação como expressão da violação de direitos humanos ${ }^{31}$. É um enfrentamento político contra arbitraridades e vulnerabilidades múltiplas e sobrepostas ${ }^{31,32}$. De fato, nas narrativas das mulheres e trabalhadores, nota-se que os aparatos repressivos e coercitivos sobre a corporeidade e a vida produzem sentidos distorcidos sobre os direitos. Nesse contexto, as violações se tornam invisíveis, isolando os sujeitos ${ }^{16}$.

Observou-se como linha de fuga que algumas mulheres decidem parir em maternidades que resistem mais às interferências judiciais, ou até mesmo vão para municípios onde a mão do Estado segregador não esteja tão presente. A evasão hospitalar, a recusa em procurar algumas maternidades e o deslocamento para outros municípios são estratégias utilizadas pelas mães para não terem seus filhos retirados de $\mathrm{si}^{17,23}$.

E tem as mães que têm uma expectativa de cuidar daquele filho. Geralmente são mães que já perderam a guarda parcial ou total dos filhos que elas geraram, e nesse caso, dessas que veem que já existe um risco muito grande de perder novamente a guarda, muitas evadem. A gente já teve situações aqui supercomplexas, superdelicadas, né (gestor da maternidade 3 ).

[...] eu conheço o relato de uma mãe que se recusou a vir para a maternidade. Ela foi para a UPA, já em trabalho de parto, porque ela sabendo da portaria e sabendo... reconhecendo a vulnerabilidade da família, ela tinha medo de vir para a maternidade e perder a guarda da criança (gestor da maternidade 1$)$.

[...] o que a gente tem percebido também num movimento das gestantes no município é não procurarem os serviços de saúde por medo de terem os seus filhos recolhidos. Então o que na verdade viria como uma forma ilusória de facilitar a entrada dessas mulheres na rede, na verdade dificulta (trabalhadora do Consultório de Rua).

Não obstante, vozes femininas ecoam nas narrativas e reivindicam o direito à maternidade enquanto desejo produzido em suas trajetórias.

As mulheres estão sofrendo, indo atrás. Mas elas não têm meios para falar, quem fala mais é quem tem algum capital social. A maioria luta numa esfera de possibilidades muito restrita, muito silenciada (professora universitária e representante do Movimento Feminista)

Movimentos de resistência mostraram que a presença de diálogos intersetoriais, despidos de verdades institucionais, constituem alternativa para viabilizar a superação das discriminações e das condições de vulnerabilidade ${ }^{23}$. Em BH, entre 2016 e 2018, o movimento "De quem é este bebê" ${ }^{33}$ envolveu trabalhadores do SUS BH, do Conselho Municipal de Saúde, dos conselhos regionais de Assistência Social e Psicologia, dos fóruns de Saúde Mental e de População de Rua, da Defensoria Pública e de grupos da UFMG das áreas da saúde e do direito, entre outros, e mobilizou sensibilidades, afetos e conhecimentos que acionaram ações criativas de resistência.

Existe uma rede de apoio que atende a telefonemas, e um liga pra outro, pede pra saber quem tá na maternidade. É uma coisa muito individual, lu- 
tamos individualmente pra ajudar essas mulheres. Tem vários profissionais de saúde tentando dar um jeito. Até quem tá num espaço com mais poder não consegue fazer quase nada, imagina essas mulheres que ainda estão usando álcool e drogas, as mulheres pobres que estão morando na rua (professora universitária e representante do Movimento Feminista).

Vai abrir, a gente vai atrás, e a gente vai cuidar porque é dessa que eu quero ver se a gente dá conta de cuidar. Eaí, gente, a gente cuida, tem uns casos... a gente cuida... segunda-feira da semana passada, eu recebi aqui uma visita de uma bebezinha que vai fazer três meses, de uma mãe usuária, moradora de rua, sabe qual que foi a única diferença? Que a gente conseguia cuidar dela, sabe? (trabalhadora 2 da UBS).

Em síntese, a produção de ofertas mais cuidadoras para pessoas em situações de vulnerabilidade, sejam institucionais ou não, têm se constituído como espaços de resistência aos efeitos da necro/biopolítica. Pelbart ${ }^{14}$ reitera que a subjetividade de alguém em revolta é também produto de forças externas que contribuem para movimentos possíveis. Ações de trabalhadores, gestores e sociedade civil no sentido de tentar produzir rede e cuidado em saúde constituem exemplos dessa percepção, despontando como esperança para essas cidadãs que se sentem abandonadas pelo poder público. São projetos de cuidado construídos de modo compartilhado, a partir de ofertas que conversam com os desejos e as potências das mulheres, abrindo caminho para ressignificações de seus modos de estar no mundo.

O enlace produzido a partir das experiências singulares das mães e das ações dos movimentos sociais mostra a potência da subjetividade humana diante do arbítrio. Na prática, os desafios que envolvem o exercício da maternidade no Brasil estão alinhados às adversidades decorrentes do contexto sócio-histórico no qual o país está inserido. Refletir sobre os processos discriminatórios que envolvem a maternidade é também mergulhar em esforços para buscar uma compreensão acerca da complexidade da produção do campo social brasileiro. É buscar uma inquietude necessária para modificar o que persiste do passado em termos de segregação e exclusão social.

\section{Considerações finais}

A defesa da vida de todos constitui princípio elementar para a efetivação de atos cuidadores e promotores de conexões que ampliam a potência de vida das mulheres, incluindo a possibilidade de viverem com seus filhos. Indígenas, negras e pobres estão mais expostas a ações estatais e a julgamentos da sociedade, o que pode levar à retirada de seus filhos. No Brasil, as possibilidades de vivenciar a maternidade não são as mesmas para todas as mulheres.

Um ideal de maternidade distante das possibilidades de vida da maioria das mulheres brasileiras, que sequer é cobrado na mesma intensidade de mulheres de outros extratos sociais, a criminalização da pobreza, as discriminações raciais e de gênero, ao lado das tentativas de silenciar vozes que expõem violações de direitos, configuram um quadro que convoca resistências para enfrentar o intolerável.

Isso posto, a defesa do direito à reconstrução de vidas vulnerabilizadas inclui o direito à maternidade. Também deve abranger a autonomia sexual e reprodutiva e a necessidade de superar opressões que se refletem no conceito de mãe, categoria globalizada e marcada por relações de poder que condicionam e limitam possibilidades de vida e modos de se relacionar.

Nesse debate, cabe destaque às lutas feministas, que propõem enfrentamentos às adversidades que acompanham as possibilidades de ser mulher e mãe - pobre, negra, indígena ou em situações diversas de vulnerabilidade no Brasil -, e muitas vezes mães solo, mesmo quando inseridas no mercado de trabalho. Trata-se de uma pauta complexa, que envolve esforços em prol de uma sociedade capaz de suspender o tom nebuloso e ameaçador que as leituras da biopolítica no país expõem no momento atual.

Nesse curso, a atuação dos movimentos sociais continua sendo essencial dar voz aos acontecimentos das vidas dessas mulheres e criar mecanismos coletivos para sacudir velhas ações higienistas. É crucial produzir políticas de proteção social que resguardem diferentes maneiras de existir. Negar modos de produção de vida é negar o direito à existência. Superar essas arbitrariedades envolve um comprometimento coletivo com as vidas de todos e com a produção de formas mais solidárias de produzir o mundo. 


\section{Colaboradores}

AO Jorge contribuiu na concepção, no planejamento do desenho metodológico e da coleta de dados, na supervisão, validação, análise e interpretação dos dados para o trabalho, na redação final e revisão crítica do conteúdo intelectual, e também na aprovação final da versão do manuscrito. AF Carajá atuou na concepção, coleta dos dados, análise e interpretação dos dados, redação final e aprovação final da versão a ser publicada. GM Reis trabalhou na concepção, coleta dos dados, análise e interpretação dos dados, redação e aprovação final da versão do manuscrito a ser publicada. MG Pontes contribuiu na concepção, no planejamento do desenho metodológico, na coleta dos dados, na análise e interpretação dos dados, na redação inicial e aprovação final da versão do manuscrito. LS Braga atuou na concepção, no planejamento do desenho metodológico, na análise e interpretação dos dados, na redação e aprovação final do manuscrito. MG Araujo trabalhou no planejamento do desenho metodológico, na análise e interpretação dos dados, na redação final e na aprovação do manuscrito a ser publicado. S Lansky contribuiu com a análise e interpretação dos dados, com a redação final e a aprovação final do manuscrito. LCM Feuerwerker atuou no planejamento do desenho metodológico, na análise e interpretação dos dados, na redação final e na aprovação da versão do manuscrito a ser publicada.

\section{Referências}

1. Pereira PJ, Oliveira MCFA. Adoção de crianças e adolescentes no Brasil: sua trajetória e suas realidades. Campinas: Núcleo de Estudos de População Elza Berquó, Unicamp; 2016.

2. Carajá AF. Diário Cartográfico das mães que perdem seus filhos e filhas pelas mães do Estado: paisagens que se repetem[dissertação]. Belo Horizonte: Faculdade de Medicina, Universidade Federal de Minas Gerais; 2019. [acessado 2021 Jan 14]. Disponível em: https:// repositorio.ufmg.br/handle/1843/1/browse?type=author\&order $=$ ASC\&rpp $=20$ \&value $=$ Adriana + Fernandes+Caraj\%C3\%A1

3. Bosi MLM, Machado MT. Amamentação: um resgate histórico. Caderno Esp - Escola de Saúde Pública do Ceará 2005 [periódico na internet]. [acessado 2020 Jun 20]. Disponível em: http://www.aleitamento.com.br/ upload\%5Carquivos\%5Carquivo1_1688.pdf

4. Reina E. Cativeiro sem fim: as histórias dos bebês, crianças e adolescentes sequestrados pela ditadura militar no Brasil. São Paulo: Alameda; 2019.

5. Brasil. Ministério Público Federal. Relatório Figueiredo [documento online]; 2019. [acessado 2019 Mai 1]. Disponível em: http://www.mpf.mp.br/atuacao-tematica/ccr6/dados-da-atuacao/grupos-de-trabalho/ violacao-dos-direitos-dos-povos-indigenas-e-registro-militar/relatorio-figueiredo

6. Arbex D. Holocausto brasileiro. São Paulo: Geração Editorial; 2013.

7. Monteiro YN. Violência e profilaxia: os preventórios paulistas para filhas e filhos de portadores de hanseníase. Saúde e Sociedade 1998; 7(1):3-26.

8. Jorge AO, Merhy EE, Pontes MG. Introduzindo a pesquisa: uma trajetória de encontros. Saúde em Redes 2018; 4(Supl. 1):9-26.

9. Belloc MM, Cabral KV, Oliveira CS. A desmaternalização das gestantes usuárias de droga: violação de direitos e lacuna do cuidado. Saúde em Redes 2018; 4(Supl. 1):37-50.

10. Silveira PM, Hernanez ML, Furtado LAC, Feuwerwerker LCM, Moreno HV, Santos HE. Oh pedaço de mim, oh metade amputada de mim... Saúde em Redes 2018; 4(Supl. 1):51-59.

11. Chagas MC, Abrahão AL. Desobediência civil na produção singular do cuidado em rede: outros olhares para mães usuárias de drogas. Saúde em Redes 2018; 4(Supl. 1):61-74.

12. Moebus RLN, Merhy EE, Silva E. O usuário cidadão como guia. Como pode a onda elevar-se acima da montanha. In: Merhy EE, Baduy RS, Seixas CT, Almeida DES, Slomp Júnior H, organizadores. Avaliação compartilhada do cuidado em saúde: surpreendendo o instituído nas redes. Rio de Janeiro: Editora Hexis; 2016. p. 43-53.

13. Rolnik S. Cartografia sentimental. Porto Alegre: Editora da UFRGS; 2016.

14. Pelbart PP. O avesso do niilismo: cartografias do esgotamento. São Paulo: n-1 edições; 2013. 
15. Abrahão AL, Merhy EE, Gomes MPC, Tallemberg C, Chagas MC, Rocha M, Santos NPL, Silva E, Vianna L. $\mathrm{O}$ pesquisador in-mundo e o processo de produção de outras formas de investigação em saúde. In: Merhy EE, Baduy RS, Seixas CT, Almeida DES, Slomp Júnior $\mathrm{H}$, organizadores. Avaliação compartilhada do cuidado em saúde: surpreendendo o instituído nas redes. Rio de Janeiro: Editora Hexis; 2016. p.22-30.

16. Argolo MM, Araújo R. Construções de gênero das mulheres/mães negras no contexto da violência policial contra adolescentes e jovens. Seminário Internacional Fazendo Gênero 11 \& 13th Women's Worlds Congress [anais eletrônicos], Florianópolis; 2017. [acessado 2020 ago 31]. Disponível em: http:// www.en.wwc2017.eventos.dype.com.br/resources/ anais/1503883048_ARQUIVO_CONSTRUCOESDEGENERODASMULHERES.docxversao3.pdf

17. Reis GM. Mães órfãs: cartografia das tensões e resistências ao abrigamento compulsório de bebês em Belo Horizonte [dissertação]. Belo Horizonte: Faculdade de Medicina, Universidade Federal de Minas Gerais; 2019.

18. Foucault M. Segurança, território e população. São Paulo: Martins Fontes; 2008.

19. Badinter E. O conflito, a mulher e a mãe. Rio de Janeiro: Record; 2010.

20. Oliveira DS. Vivências e enfrentamentos de mulheres que usam drogas no exercício da maternidade [dissertação]. Bahia: Universidade Federal da Bahia, Escola de Enfermagem; 2016.

21. Orsine AOL, Silva KL, Jorge AO, Pereira MO. Sofia: narrativa de uma história de abandono e sequestro dos direitos de vir a ser. Saúde em Redes 2018; 4(Supl. 1):75-85.

22. Delphy C. Patriarcado (teorias do). In: Hirata H, organizador. Dicionário Crítico do Feminismo. São Paulo: Unesp; 2009.

23. Pontes MG. Mães órfãs: produzindo novos olhares a partir de modos de existência e resistência singulares [dissertação]. Belo Horizonte: Faculdade de Medicina, Universidade Federal de Minas Gerais; 2019.

24. Akotirene C. Interseccionalidade: feminismos plurais. São Paulo: Sueli Carneiro; Pólen; 2019.
25. Davis A. Mulheres, raça e classe. São Paulo: Boitempo; 2016.

26. Butler J. Quadros de guerra: quando a vida é passível de luto. Rio de Janeiro: Civilização Brasileira; 2015.

27. Dardot P, Laval C. A nova razão do mundo: ensaio sobre a sociedade neoliberal. São Paulo: Boitempo; 2016.

28. Souza TP. Estado e sujeito: a saúde entre a micro e macropolitica de drogas. Campinas: Editora Hucitec; 2018.

29. Franco TB. Fobia de Estado e a resistência ao recolhimento compulsório de bebês. Saúde em Redes 2018; 4(Supl.1):85-98.

30. Reis SEH, Bonadio IC, Tsunechiro MA, Merighi MAB. O cotidiano de mulheres grávidas moradoras no alojamento de uma maternidade social. Texto Contexto Enferm 2008; 17(3):492-501.

31. Crenshaw K. Documento para o Encontro de Especialistas em Aspectos da Discriminação Racial Relativos ao Gênero. Estudos Feministas 2002; 10(1º semestre):171-188.

32. Hirata H. Gênero, classe e raça: interseccionalidade e consubstancialidade das relações sociais. Tempo Soc 2014; 26(1): 61-73.

33. Karmaluk C, Lansky S, Parizzi M, Batista G. "De quem é esse bebê?: movimento social de proteção do direito de mães e bebês juntos, com vida digna! Saúde em Redes 2018; 4(Supl. 1):169-189.

Artigo apresentado em 21/07/2020

Aprovado em 07/01/2021

Versão final apresentada em 09/01/2021

Editores-chefes: Romeu Gomes, Antônio Augusto Moura da Silva 